\title{
Older adults with Alzheimer disease, comorbid arthritis and prescription of psychotropic medications
}

\author{
Judith E Balfour MA ${ }^{1}$, Norm O'Rourke PhD ${ }^{2}$
}

\begin{abstract}
JE Balfour, N O'Rourke. Older adults with Alzheimer disease, comorbid arthritis and prescription of psychotropic medications. Pain Res Manage 2003;8(4):198-204.
\end{abstract}

OBJECTIVES: It is assumed that analgesia is underutilized among those with Alzheimer disease and that these patients may be inappropriately prescribed neuroleptics and benzodiazepines. The current study examines this assertion.

DESIGN: For this study, prescription levels of analgesics and psychotropic medications for Alzheimer disease patients with $(n=245)$ and without $(\mathrm{n}=215)$ musculoskeletal conditions (ie, arthritis or rheumatism) are compared.

SETTING: A national sample of community dwelling and institutionalized older adults was identified from the Canadian Study of Health and Aging* (CSHA).

PARTICIPANTS: Persons from 36 cities and surrounding rural areas over 64 years of age were randomly identified for the CSHA from government health records in all but one province.

MEASUREMENTS: Prescribed analgesic and psychotropic medications were examined, as well as dementia severity and dementia related behavioural disturbance.

RESULTS: Less than half of Alzheimer patients with arthritis or rheumatism were treated for pain (ie, 109 of 245 patients); they were also more likely to be prescribed benzodiazepines compared with Alzheimer patients without musculoskeletal conditions (subsequent to initial consideration for analgesia, dementia severity and dementiarelated behaviours; $\left.\Delta \chi^{2}[\Delta \mathrm{df}=1]=3.97, \mathrm{P}=0.046\right)$.

CONCLUSIONS: These findings are in accord with prior research attesting to the undertreatment of pain among older adults. These results can be generalized with greater confidence, given the random composition of the patient sample.

\section{Key Words: Dementia; Older adults; Pain; Pharmacotherapy}

\section{Maladie d'Alzheimer, arthrite et psychotropes}

OBJECTIF : Vérifier l'hypothèse selon laquelle les analgésiques sont sous-utilisés chez les patients atteints de la maladie d'Alzheimer et chez qui les prescriptions de neuroleptiques et de benzodiazépines ne sont pas toujours appropriées.

PLAN D'ÉTUDE : Nous avons relevé les prescriptions d'analgésiques et de psychotropes faites à des patients atteints de la maladie d'Alzheimer et comparé leur nombre entre ceux qui souffraient de maladies musculosquelettiques $(n=245)$ (arthrite ou rhumatisme) et ceux qui n'en souffraient pas $(\mathrm{n}=215)$.

MILIEU : Échantillon national de personnes âgées vivant dans la collectivité ou dans des établissements, constitué à partir de l'Étude sur la santé et le vieillissement au Canada*.

PARTICIPANTS : Des personnes âgées de plus de 64 ans et vivant en milieu urbain ou rural (36 agglomérations) ont été sélectionnées au hasard pour l'Étude à partir des archives médicales des régimes publics d'assurance-maladie dans toutes les provinces, sauf une.

MESURES : Nous avons examiné les prescriptions d'analgésiques et de psychotropes, ainsi que le degré de gravité de la démence et les troubles de comportement associés.

RÉSULTATS : Moins de la moitié des patients atteints de la maladie d'Alzheimer et souffrant d'arthrite ou de rhumatisme ont été traités pour la douleur (109 patients sur 245); ils étaient également plus susceptibles de recevoir des benzodiazépines que les patients atteints de la maladie d'Alzheimer mais ne souffrant pas de maladie musculo-squelettique (après l'évaluation initiale des besoins d'analgésiques, du degré de gravité de la démence et des troubles de comportement associés; $\Delta \chi^{2}[\Delta \eta=1]=3,97$; $p=0,046)$,

CONCLUSIONS : Les résultats confirment les tendances observées dans des études antérieures selon lesquelles la douleur n'est pas traitée suffisamment chez les patients âgés. Par ailleurs, la généralisation des résultats obtenus peut gagner en confiance étant donné la composition aléatoire de l'échantillon.
Fidemiological estimates suggest that $8 \%$ of Canadians Eover 64 years of age meet the diagnostic criteria for Alzheimer disease or a related disorder (1). Given that age represents the greatest risk factor for dementia, prevalence rates for neurodegenerative disorders such as Alzheimer disease are expected to double by 2021 (1). Although some reports suggest that a history of musculoskeletal conditions such as arthritis and associated anti-inflammatory drug use reduce the risk of dementia, a significant percentage of Canadians are diagnosed with both conditions (2) and the numbers are expected to increase substantively in the coming years.

Reported incidence rates of chronic pain among communitydwelling older adults range from $25 \%$ to $50 \%$ (3-5), while among nursing home residents, estimates are as high as $80 \%$

*The Canadian Study of Health and Aging (CSHA) was funded by the Senior's Independence Research Program, administered by the National Health Research Development Program of Health Canada (NHRDP Project No 6606-3954 MC(S)). The CSHA was coordinated through the University of Ottawa and the Canadian Government's Laboratory Centre for Disease Control

${ }^{1}$ Faculty of Pharmaceutical Sciences, University of Toronto, Toronto, Ontario; ${ }^{2}$ Gerontology Research Centre and Programs, Simon Fraser University at Harbour Centre, Vancouver, British Columbia

Correspondence: Dr Norm O'Rourke, Gerontology Research Centre and Programs, Simon Fraser University at Harbour Centre, 515 West

Hastings Street, Suite \#2800, Vancouver, British Columbia V6B 5K3. Telephone 604-291-5175, fax 604-291-5066, e-mail ORourke@sfu.ca 
(6). In both populations, it is widely believed that musculoskeletal conditions such as arthritis and rheumatism are the predominant causes of pain $(3,4,6-10)$.

Despite the wide prevalence of these conditions, evidence suggests that older persons $(9,11,12)$, and particularly those with cognitive loss, are at increased risk for undertreatment of pain (13-15). A considerable body of evidence links musculoskeletal pain with decreased health and well-being, increased rates of clinical depression, sleep disturbances, decreased socialization, and increased health care costs $(6,16)$, suggesting that the undertreatment of pain has significant consequences. Ferrell (17), for instance, contends that $45 \%$ to $80 \%$ of nursing home residents may suffer decreased quality of life and diminished functional ability as a result of inadequate pain management.

One explanation for this phenomenon pertains to the assessment of pain. For pain to be treated, it must first be recognized. Unfortunately, diagnostic sensitivity is complicated by the fact that much of pain assessment involves self-reporting. Among those with cognitive loss, deterioration of language skills, such as the ability to conceptualize and express emotion or word finding difficulties, can impede verbal reporting (18-20). Impaired capacity for abstraction may further render comparative evaluation of the pain experience difficult, if not impossible. Also, patients may deny experiencing pain because they do not remember prior episodes due to antegrade amnesia.

A number of researchers have recognized the limitations of pain assessment tools reliant on verbal self-reporting for use with cognitively impaired patients $(13,17,21)$. While some have employed a limited number of nonverbal assessment tools such as the Facial Action Coding System (13) and visual analog scales (21), the clinical evaluation of pain among patients with cognitive impairment often relies on the interpretation of behavioural expressions of pain which may include vocalizations such as crying, screaming or moaning, facial expressions such as grimacing or wincing, increased restlessness, irritability and aggression, and resistance to personal care $(15,22-25)$. Since persons with dementia frequently exhibit these behaviours, the possibility exists for misinterpretation (26).

Preconceived attitudes about elderly persons with dementia may further affect the assessment and treatment of pain. Some health care providers may hold the erroneous view that, because of both age- and disease-related neurological changes, older persons with cognitive loss do not experience pain as acutely as their younger counterparts or those free of cognitive impairment (25). Although Alzheimer disease is associated with atrophy of various brain regions involved in pain processes (27-29), the somatosensory complex tends to remain intact. As a result, pain sensation is generally preserved. Specifically, the portion of the spinothalamic tract responsible for the sensory discriminative components of pain projects to the ventroposterior and posterior thalamus and ends in the somatic cortical regions which rarely undergo substantial deterioration (27-29). Even though persons with Alzheimer disease may have difficulty describing the nature, frequency and severity of their pain, we cannot assume that the experience of pain decreases as a function of dementing processes $(13,30)$.

As previously noted, pain-related behaviour might be misinterpreted as a consequence of dementia (31). For instance, if an Alzheimer patient becomes agitated or displays aggressive behaviour due to pain, this may be labelled as a behavioural manifestation of neurodegeneration and no further explanation is therefore sought $(26,32)$. Indeed, some researchers contend that untreated pain may be an underlying cause of aggressive behaviour and other behavioural symptoms among those with cognitive impairment $(19,26,33)$.

Symptoms such as aggression and agitation are commonly treated with psychotropic medications, specifically neuroleptics and benzodiazepines (34-36). The neuroleptics appear to be modestly effective in the management of aggression and agitation among patients with dementia (eg, a suggested starting dose of $0.5 \mathrm{mg} /$ day for haloperidol [37]). Benzodiazepines have demonstrated modest efficacy in short term therapy for the reduction of agitation (recommended starting doses of $0.5 \mathrm{mg} / \mathrm{day}$ for alprazolam and lorazepam, and $10 \mathrm{mg} /$ day for oxazepam [38]).

However, these pharmacological agents are associated with numerous adverse effects, including extrapyramidal symptoms (eg, dystonia or spasms, akathesia or restlessness), tardive dyskinesia, ataxia, light-headedness, and increased cognitive loss (39-46). Other benzodiazepine side effects with older adults include increased risk of falls, antegrade amnesia, sedation, tolerance and withdrawal symptoms. This array of adverse effects limits the usefulness of psychotropic agents to proceduralassociated anxiety or short term use as required (37).

There is a limited body of evidence suggesting that cognitively impaired older adults with pain may be inappropriately prescribed psychotropic drugs $(33,38,47,48)$. The question remains, are older adults with dementia and musculoskeletal pain at increased risk for inappropriate use of psychotropic medications (ie, neuroleptics and benzodiazepines)? This question is explored in the present study. Prescription of both analgesic and psychotropic medications is examined among a randomly derived, national sample of older adults with a diagnosis of Alzheimer disease with and without rheumatism or arthritis.

With consideration for dementia related behaviours and analgesic use (ie, nonsteroidal anti-inflammatory agents [NSAIDs], acetaminophen), we hypothesized that the prescription of psychotropic medications (ie, neuroleptics and benzodiazepines) would be significantly greater for persons with rheumatism or arthritis. In other words, prescription of psychotropics would significantly differentiate older adults with Alzheimer disease and musculoskeletal conditions compared with those with Alzheimer disease alone (ie, those without arthritis or rheumatism). It was assumed that increased usage of psychotropic medication within this former patient population occurs due to the misinterpretation of pain behaviours as being dementia-related.

\section{METHODS}

\section{Canadian Study of Health and Aging}

Older adults in the community and institutional settings were recruited as part of a national epidemiological study of dementia prevalence in Canada. The methodology employed by the Canadian Study of Health and Aging (CSHA) is described elsewhere in detail (1). In brief, persons over 64 years of age were randomly identified from government health records in all provinces (except Ontario, where enumeration records were used). A total of 9008 community-dwelling older adults underwent clinical screening during which the Modified Mini-Mental State Examination (3MS) (49) was administered. Scores on the 3MS range from 0 to 100, with lower totals suggestive of cognitive impairment (50).

Community-dwelling participants scoring below 78 of 100 on the 3MS and all those in institutions were invited to undergo clinical examination ( $\mathrm{n}=2928)$. Interdisciplinary teams composed of a physician, a neuropsychologist, a nurse, and/or a psychometrician 
TABLE 1

Descriptive features of study participants $(n=460)$

\begin{tabular}{|c|c|c|c|c|c|c|c|}
\hline \multirow{2}{*}{\multicolumn{2}{|c|}{ Age of participants (years) }} & Mean & SD & Skewness & Kurtosis & Minimum & Maximum \\
\hline & & 84.33 & 6.9 & -0.1 & -0.05 & 66 & 104 \\
\hline \multicolumn{2}{|c|}{ Dementia Behaviour Disturbance Scale } & 19.14 & 13.16 & 1.02 & 1.28 & 0 & 76 \\
\hline \multicolumn{2}{|c|}{ Acetaminophen } & 0.37 & 0.55 & 1.5 & 3.63 & 0 & 4 \\
\hline \multicolumn{2}{|c|}{ Neuroleptic medications } & 0.21 & 0.44 & 1.92 & 2.81 & 0 & 2 \\
\hline Mild & 116 & & & & & & \\
\hline Moderate & 177 & & & & & & \\
\hline Severe & 167 & & & & & & \\
\hline Total & 460 & & & & & & \\
\hline
\end{tabular}

The distribution of nonsteroidal anti-inflammatory agents (NSAIDs) indicates positive kurtosis outside of normal parameters. Logarithmic transformation of NSAID scores to attain a more normal distribution did not significantly alter study findings.

reached a consensus diagnosis based on all clinically relevant information (51). Those receiving a dementia diagnosis were categorized with mild, moderate or severe impairment on the basis of the American Psychiatric Association criteria (52).

\section{Selected study participants}

Inclusion in the current study was restricted to CSHA participants who received a diagnosis of probable or possible Alzheimer disease (53) as opposed to unspecified, vascular or mixed clinical presentations. In contrast to these latter conditions, the neuropathology of Alzheimer disease is characterized by diffuse atrophy of the cerebral cortices resulting in a gradual deterioration of cognitive function across domains (54).

Conversely, vascular dementia tends to be associated with progressive, yet stepwise, deterioration of cognition due to multiple, diffuse brain infarcts. As a result, behaviour change may be more abrupt and accurately identified as dementia related (ie, caregivers and clinicians are more likely to take notice of these more pronounced changes in behaviour and cognition, and accurately attribute these to vascular pathology). Furthermore, the variable distribution of brain lesions tends to result in circumscribed deficits as a function of the location of damage (54). Thus, the clinical presentation of vascular dementia may be more variable than the more homogeneous nature of Alzheimer disease (55). Finally, patients with vascular dementia may be prescribed acetylsalicylic acid (ASA) for reasons other than analgesia (ie, for prevention of cerebrovascular accidents). Given these factors, the decision was made to restrict inclusion in the current study to CSHA participants with a diagnosis of Alzheimer disease.

As a result, 460 persons were identified who received a diagnosis of probable or possible Alzheimer disease (124 men, 336 women). The high percentage of women in this sample $(73 \%)$ is likely due to the advanced age of these patients (mean $=84.335$ years, $\mathrm{SD}=6.905)$. Their level of educational attainment was on average 8.413 years $(\mathrm{SD}=3.813)$. The majority lived within institutional settings ( 253 or $55 \%$ ) while the remainder continued to reside in the community (207 or $45 \%$ ).

Consistent with prior estimates, 245 or $53.3 \%$ of selected patients had arthritis or rheumatism ( $n=245$ with musculoskeletal conditions, $\mathrm{n}=215$ without). Due to cognitive loss, information regarding chronic health conditions was obtained from proxy informants for the vast majority of these participants (eg, primary caregivers). See Table 1 for descriptive statistics.

\section{Study variables}

Analgesic medications: NSAIDs (eg, naproxen, diclofenac, ibuprofen) and acetaminophen are recommended treatments for the pain associated with arthritis and rheumatism (56-59). Three additional types of analgesics: opioids, muscle relaxant and analgesic compounds, as well as ASA compounds were not included in the current analyses. Opioid analgesics and muscle relaxants were excluded because of the low frequency of use within the sample (11 patients only). While the use of ASA compounds was higher than that of the opioid and muscle relaxants, bivariate analyses failed to demonstrate statistically significant relationships between these analgesics and either cognitive status or the presence of arthritis or rheumatism. As a result, ASA compounds were also excluded from the analyses.

Psychotropic medications: Neuroleptics and benzodiazepines were chosen as the psychotropic agents of interest on the basis of their use to mitigate dementia-related behaviours. Other agents used to manage agitation and aggression, including carbamezepine, valproic acid, buspirone and trazadone, have other therapeutic indications such as seizure disorders and depression, and would therefore introduce numerous confounding variables (ie, prescription to treat conditions other than pain).

Neuroleptics are classified as either typical (traditional) or atypical (second generation). Typical neuroleptics include: phenothiazines (eg, chlorpromazine, thioridazine, perphenazine), thioxanthenes (eg, thiothixene), and butyrophenones (eg, haloperidol). Atypical neuroleptics include the newer agents clozapine, risperidone, olanzapine and quetiapine. The primary difference between the typical and atypical neuroleptics is that the latter cause fewer extrapyramidal symptoms and tardive dyskinesia, and appear to be more effective in the treatment of negative psychotic symptoms such as flat affect (39).

Individual benzodiazepines differ with respect to potency and pharmacokinetics, and are divided into three categories on the 
basis of half-life $\left(t_{1 / 2}\right)$. Long acting benzodiazepines (eg, diazepam and flurazepam) have a $t_{1 / 2}$ of approximately $100 \mathrm{~h}$. Intermediate acting agents have a $\mathrm{t}_{1 / 2}$ ranging from $5 \mathrm{~h}$ to $15 \mathrm{~h}$ (eg, oxazepam) and $20 \mathrm{~h}$ to $80 \mathrm{~h}$ (eg, alprazolam, lorazepam and temazepam). Midazolam $\left(\mathrm{t}_{1 / 2}=1 \mathrm{~h}\right.$ to $\left.4 \mathrm{~h}\right)$ and triazolam $\left(\mathrm{t}_{1 / 2}=1.5 \mathrm{~h}\right.$ to $\left.5 \mathrm{~h}\right)$ are examples of short acting agents (60). In general, longer acting agents also produce active metabolites that extend their already long $t_{1 / 2}$. Moreover, the $t_{1 / 2}$ of these agents tend to be significantly elongated in older adults, which complicates dosing $(39,61)$. Although the CSHA sought information regarding prescribed psychotropic medications, specific dose information was not obtained.

\section{Dementia Behavior Disturbance Scale}

For CSHA participants receiving a dementia diagnosis, proxy informants (eg, informal or formal caregivers) were administered the Dementia Behavior Disturbance Scale (DBD) (62). This measure was developed to assess problematic behaviours directly related to neurodegenerative illness. The DBD consists of 28 questions pertaining to problematic behaviours to which informants are asked to rate how frequently each behaviour has occurred in the past week (eg, "Hoards things for no obvious reason"; "Makes unwarranted accusations"). Responses are reported along a 5-point Likert-type scale (never [0] to all of the time [4]). Possible scores range from 0 to 112, with higher totals reflecting greater behavioural disturbance.

In contrast to previous measures, the DBD was developed with a more narrow definition of behavioural disturbance to focus upon the specific manifestations of dementia syndromes. Items, therefore, do not tap functional and somatic symptoms nor cognitive impairment as Baumgarten and colleagues (62) contend that these features are related to illness severity as opposed to behavioural disturbance.

From the initial validation study, responses to the DBD appear to possess optimal internal consistency $(\alpha=0.83)$. Among CSHA participants, Cronbach's alpha has been reported as $\alpha=0.86$ (63). Test-retest reliability over a two-week period was reported as $r=0.71(62)$. Construct validity has been established relative to the Behavior and Mood Disturbance Scale, as responses to these two measures are strongly correlated $(r=0.73)$. These findings suggest that responses to the DBD provide a valid and reliable index of problematic behaviours attributable to neurodegenerative illness.

\section{Data analyses}

As stated, it was hypothesized that prescription of psychotropic medication would significantly distinguish Alzheimer patients with and without musculoskeletal conditions. For the present study, this assertion was tested by means of discriminant function analysis. This analytic procedure is deemed an appropriate statistical procedure to predict membership in naturally occurring groups of unequal size (64).

With consideration of analgesia, dementia severity and dementia-related behaviours, the authors hypothesized that prescription of neuroleptics and benzodiazepines would differ between Alzheimer patients with and without arthritis or rheumatism. More precisely, psychotropic drug use was hypothesized to be significantly greater for those with both Alzheimer disease and a musculoskeletal condition. The authors assumed that this result reflects a tendency to misinterpret pain as dementia related behavioural disturbance among patients with Alzheimer disease.
TABLE 2

\begin{tabular}{|c|c|c|}
\hline $\begin{array}{l}\text { Selected CSHA } \\
\text { participants }(n=460)\end{array}$ & $\begin{array}{c}\text { With arthritis/ } \\
\text { rheumatism }(n=245)\end{array}$ & $\begin{array}{l}\text { Without arthritis } / \\
\text { rheumatism }(n=215)\end{array}$ \\
\hline Age of participants, mean (SD) & $85.094(6.732)$ & $83.470(7.013)$ \\
\hline Years of education, mean (SD) & $8.303(3.722)$ & $8.534(3.916)$ \\
\hline DBD, mean (SD) & $18.935(12.910)$ & $19.372(13.463)$ \\
\hline NSAIDs & 23 & 9 \\
\hline Acetaminophen & 95 & 60 \\
\hline Neuroleptic medications & 46 & 43 \\
\hline Benzodiazepines & 54 & 34 \\
\hline
\end{tabular}

CHSA Canadian Study of Health and Aging; DBD Dementia Behavio Disturbance Scale; NSAID Nonsteroidal anti-inflammatory agents

\section{RESULTS}

\section{Descriptive statistics}

As previously noted, 245 or $53.3 \%$ of selected patients were identified as having arthritis or rheumatism as well as Alzheimer disease. Although those with musculoskeletal conditions were somewhat older (mean $=85.094$ years) than those without $($ mean $=83.470$ years; $t[458]=2.532, P=0.012$ ), levels of dementia severity did not differ between groups $\left(\chi^{2}[2\right.$, $\mathrm{n}=460]=0.149, \mathrm{P}=0.928)$, nor impairment in ability to perform activities of daily living $\left(\chi^{2}[6, \mathrm{n}=459]=2.116, \mathrm{P}=0.714\right)$. Another notable observation is that less than half of all patients with arthritis or rheumatism were receiving either acetaminophen or NSAID medications (44.5\%) (Table 2).

However, $19.3 \%$ (or 89 ) of these patients with Alzheimer disease were prescribed at least one neuroleptic medication. The percentage of patients prescribed at least one benzodiazepine was also substantial (19.1\% or 88 patients). The three most commonly prescribed benzodiazepines were lorazepam $(n=35$, $7.6 \%)$; oxazepam $(n=20,4.3 \%)$; and triazolam $(n=14,3.0 \%)$. Nine patients $(1.9 \%)$ were prescribed long-acting benzodiazepines (eg, diazepam, flurazepam). All but one patient prescribed multiple benzodiazepines had arthritis or rheumatism.

\section{Discriminant function analysis}

As previously stated, it was hypothesized that prescription of psychotropic medication would significantly distinguish Alzheimer patients with $(\mathrm{n}=245)$ and without musculoskeletal conditions $(n=215)$. This was tested by means of discriminant function analysis.

First, prescription for analgesic medications was considered to control for appropriate pain treatment. Even though less than half of those with arthritis or rheumatism were prescribed either acetaminophen or an NSAID, these medications significantly distinguished those with and without a musculoskeletal condition $\left(\chi^{2}[2, \mathrm{n}=460]=11.469, \mathrm{P}=0.003\right)$

Dementia behavioural disturbance and severity of dementia symptoms were also considered to control for possible differences between groups. As assumed, these dementia-related features did not differ as a function of comorbid pain $\left(\Delta \chi^{2}[\Delta \mathrm{df}=2]=0.367, \mathrm{P}=0.832\right)$.

Treatment of agitation and problematic behaviour is a legitimate reason to prescribe psychotropic medication to persons with Alzheimer disease $(50,51)$; thus, neuroleptics and benzodiazepines were both included to distinguish between 
appropriate and inappropriate use of psychotropic medication in this patient population.

Contrary to hypothesis, prescription of neuroleptic medications did not distinguish between Alzheimer patients with and without musculoskeletal conditions $\left(\Delta \chi^{2}[\Delta \mathrm{df}=1]=0.117\right.$, $\mathrm{P}=0.733)$. However, prescription of benzodiazepines did significantly distinguish between those with arthritis or rheumatism and those without a musculoskeletal condition (22\% versus $\left.16 \% ; \Delta \chi^{2}[\Delta \mathrm{df}=1]=3.969, \mathrm{P}=0.046\right)$. This finding suggests that the prescription of benzodiazepines for Alzheimer patients is significantly greater for those with arthritis or rheumatism (subsequent to consideration of analgesia, behavioural disturbance and dementia severity, and prescription of neuroleptic medications).

This finding provides indirect support for the hypothesis that pain may be misidentified among Alzheimer patients with a musculoskeletal condition and muted with benzodiazepines as opposed to treatment with analgesics. Of the patients with arthritis or rheumatism, those not treated for pain are more likely to be prescribed benzodiazepines compared with those receiving analgesic medications $(t[243]=1.949, \mathrm{P}=0.052)$. This finding suggests that these patients continue to experience pain, though the expression of pain behaviours is attenuated (ie, suffer in silence).

\section{DISCUSSION}

The first finding of note from this study is that the percentage of patients with arthritis or rheumatism receiving analgesic medication was surprisingly low. Less than half of the selected patients with a musculoskeletal condition were prescribed analgesic medication. This suggests the presence of untreated (or mistreated) pain for considerable numbers of these individuals. This may be because NSAIDs, in particular the traditional agents available at the time the data were collected, must be used cautiously with frail elderly patients due to serious adverse effects such as gastrointestinal bleeding and renal failure $(65,66)$. As a result, the most recent guidelines published by the American Geriatric Society Panel on Persistent Pain in Older Persons recommends acetaminophen as firstline treatment for mild to moderate musculoskeletal pain (67). Prescription of NSAIDs is warranted when treatment with maximum safe doses of acetaminophen $(4000 \mathrm{mg}$ daily, with normal renal and hepatic function) fails to achieve adequate pain control. However, more than one-half of those identified with arthritis or rheumatism in this sample took neither NSAIDs nor acetaminophen. Because dose information was not obtained for our sample, it was not possible to determine if patients taking acetaminophen received therapeutic doses.

In contrast, roughly $20 \%$ of patients were prescribed at least one benzodiazepine or neuroleptic medication (and 25 patients, or $5.4 \%$ of patients were prescribed both). This study's findings extend this observation by suggesting that pain is not only undertreated within this vulnerable population, but possibly mistreated as well.

We cannot definitively state, however, that the underand/or mistreatment of pain is due specifically to the clinical features of Alzheimer disease. In fact, this may simply reflect a pervasive pattern of suboptimal analgesia across older adult populations (68). The patient sample derived for the current study has not allowed us to directly test this hypothesis. Although there is an association between untreated pain and the prescription of benzodiazepines, a similar phenomenon may also exist among those without Alzheimer disease.

Yet, the adverse side effects of sedative medication are of particular concern with this patient population. For example, benzodiazepines are associated with ataxia, thus increasing the risk of falls and fractures (42). Also significant is the potential to exert anticholinergic (69) and adverse cognitive effects (70). Even at therapeutic levels, benzodiazepines can cause cognitive impairment in older adults $(26,43)$. Such an effect is particularly problematic for patients with pre-existing cognitive loss. Indeed, Lagnaoui and colleagues (71) demonstrated a significant association between previous benzodiazepine use and increased risk of dementia.

The specific benzodiazepines prescribed for our sample is also cause for some concern. Although the use of agents such as flurazepam and diazepam is lower than that of those with shorter $t_{1 / 2}$ (eg, lorazepam, oxazepam and temazepam), almost $2 \%$ of the study sample were prescribed long-acting benzodiazepines. These agents have extremely long $t_{1 / 2}$ among older adults, producing prolonged sedation and increased risk of falls and fractures (72). Moreover, triazolam, the third most common agent, is known to cause higher rates of antegrade amnesia and next day memory loss than any of the other benzodiazepines (60). Use of this medication is contraindicated when the individual cannot be certain of a full $7 \mathrm{~h}$ to $8 \mathrm{~h}$ of sleep. As a result, this agent is a very poor sedative-hypnotic choice for elderly patients.

\section{Study limitations}

The results of this study can be generalized with some confidence, given the random and representative nature of the CSHA sample. Moreover, clinical assessment followed by case conference ensured generally reliable and valid assignment to diagnostic category (29). However, analyses were restricted somewhat by the nature of derived data. As previously noted, the CSHA did not obtain information regarding the dose of the medications. Without this information, it was not possible to determine if therapeutic levels of drugs were administered or to compare different agents.

The CSHA dataset also lacked a measure of pain severity. Such information would have aided the assessment of the adequacy of analgesic treatment, in addition to permitting a comparison of treatment by severity of pain and severity of pain by cognitive status. Furthermore, there was no measure of the severity of musculoskeletal pain, making it impossible to compare treatment by illness severity.

Lack of a true measure of pain also meant that it was not possible to definitively delineate the presence and absence of pain. Although it is reasonable to assert that people with arthritis will experience disease-related pain $(7,9,73)$, it cannot be assumed that those without arthritis are pain-free. For instance, 64 or $29.8 \%$ of patients in this sample without arthritis or rheumatism were prescribed analgesic medication (presumably for other painful conditions). Even greater between-group differences would likely have been observed had we been able to distinguish between patients with and without all pain conditions.

A final limitation is that the CSHA dataset is now more than 10 years old. In the interim, new drugs have become available that offer greater treatment options. According to the American Geriatrics Society (65), the cyclooxygenase selective NSAIDs (eg, rofecoxib) may prove to be safer than the tradi- 
tional NSAIDs. However, this limitation does not override the significance of our findings. Even with the availability of newer and safer analgesics, they are unlikely to be used if pain is misidentified among patients with Alzheimer disease. We can hope, however, that awareness of the topic of analgesia in later life has increased in these intervening years. Further research is required to determine if this awareness has translated into appropriate clinical practice. This should be an objective of future longitudinal research examining the prevalence of pain among older adults and the efficacy of treatments.

ACKNOWLEDGEMENTS: The authors wish to acknowledge the assistance of Drs Gloria Gutman and Andrew Wister for their contributions to a previous draft of this study.

\section{REFERENCES}

1. Canadian Study of Health and Aging Working Group. Canadian Study of Health and Aging: Study methods and prevalence of dementia. CMAJ 1994;150:899-913.

2. Canadian Study of Health and Aging Working Group. The Canadian Study of Health and Aging: Risk factors for Alzheimer's disease in Canada. Neurology 1994;44:2073-80.

3. Scudds RJ, Robertson JM. Pain factors associated with physical disability in a sample of community-dwelling senior citizens. J Gerontol A Biol Sci Med Sci 2000;55:393-9.

4. Millar WJ. Chronic pain. Health Reports 1996;7:47-53.

5. Cook AJ, Rideout E, Browne G. The prevalence of pain complaints in a general population. Pain 1984;18:299-314.

6. Ferrell BA, Ferrell BR, Osterweil D. Pain in the nursing home. J Am Geriatr Soc 1990;38:409-14

7. Lansbury G. Chronic pain management: A qualitative study of elderly people's preferred coping strategies and barriers to management. Disabil Rehabil 2000;22:2-14.

8. Thomas MR, Roy R. The Changing Nature of Pain Complaints Over The Lifespan. New York: Plenum Press, 1999.

9. Ferrell BA. Pain management in elderly people. J Am Geriatr Soc 1991;39:64-73.

10. Cook AJ, Thomas MR. Pain and the use of health services among the elderly. J Aging Health 1994;6:155-72.

11. Bernabei R, Gambassi G, Lapane K, et al. Management of pain in elderly patients with cancer. J Am Med Assoc 1998;279:1877-82.

12. Gagliese L, Melzack R. The assessment of pain in the elderly. In: Mostofsky, DI, Lomranz, J, eds. Handbook of Pain and Aging. New York: Plenum Press, 1997:69-96.

13. Hadjistavropoulos T, LaChapelle DL, MacLeod F, et al. Cognitive functioning and pain reactions in hospitalized elders. Pain Res Manage 1998;3:145-51.

14. Kaasalainen S, Middleton J, Knezacek S, et al. Pain and cognitive status in the institutionalized elderly: Perceptions and interventions. Pain 1998;24:24-31.

15. Marzinski LR. The tragedy of dementia: Clinically assessing pain in the confused, nonverbal elderly. J Gerontol Nurs 1991;17:25-8.

16. Parmalee PA, Katz I, Lawton M. The relationship of pain to depression among institutionalized aged. J Gerontol Psychol Sci Soc Sci 1991;46:15-21.

17. Ferrell BA. Pain evaluation and management in the nursing home. Ann Intern Med 1995;123:681-7.

18. Parmalee PA, Smith B, Katz IR. Pain complaints and cognitive status among elderly institution residents. J Am Geriatr Soc 1993;41:517-22.

19. Buffman MD, Miaskowski C, Sands L, et al. A pilot study of the relationship between discomfort and agitation in patients with dementia. Geriatr Nurs 2001;22:80-5.

20. Clavel DS. Vocalizations among cognitively impaired elders: What is your patient trying to tell you? Geriatr Nurs 1999;20:90-3.

21. Kurlewitch H, London MR, Skakel VJ, Lundstedt GJ, Thomason H, Brummel-Smith K. Assessment of pain in cognitively impaired older adults: A comparison of pain assessment tools and their use by nonprofessional caregivers. J Am Geriatr Soc 2000;48:1607-11.

22. Sengstaken EA, King SA. The problems of pain and its detection among geriatric nursing home residents. J Am Geriatr Soc $1993 ; 41: 541-4$
23. Feldt KS, Ryden MB, Miles S. Treatment of pain in cognitively impaired compared with cognitively intact older patients with hipfracture. J Am Geriatr Soc 1998;46:1079-85.

24. Closs, SJ. Pain and elderly patients: A survey of nurses' knowledge and experiences. J Adv Nurs 1996;23:237-43.

25. Harkins SW, Price DD. Assessment of pain in the elderly. In: Turk DC, Melzack R, eds. Handbook of Pain Assessment. New York: Guildford, 1992:315-31.

26. Miller CA. Medications that may cause cognitive impairment in older adults. Geriatr Nurs 1995;16:47.

27. Huffman JC, Kunik ME. Assessment and understanding of pain in patients with dementia. Gerontol 2000;40:574-81.

28. Scherder EJA. Low use of analgesics in Alzheimer's disease: Possible mechanisms. Psychiatry 2000;63:1-12.

29. Katzman R, Jackson JE. Alzheimer's disease: Basic clinical advances. J Am Geriatr Soc 1991;39:516-25.

30. Proctor WR, Hirdes JP. Pain and cognitive status among nursing home residents in Canada. Pain Res Manag 2001;6:119-25.

31. Kitwood T. The dialectics of dementia: With particular reference to Alzheimer's disease. Ageing Soc 1990;10:177-96.

32. Horgas AL, Tsai PF. Analgesic drug prescription and use in cognitively impaired nursing home residents. Nurs Res 1998;47:235-42.

33. Olson J. Problem behavior or pain? Untreated pain can lead residents with dementia to strike out. Contemp Longterm Care 2000;23:31.

34. Salzman C. Treatment of the agitation of late-life psychosis and Alzheimer's disease. Eur Psychiatry 2110;16:S25-8.

35. Sourial R, McCusker J, Cole M, et al. Agitation in demented patients in an acute care hospital: Prevalence, disruptiveness and staff burden. Int Psychogeriatr 2001;13:182-97.

36. Draper B, Snowdon J, Meares S, et al. Case-controlled study of nursing home residents referred for treatment of vocally disruptive behavior. Int Psychogeriatr 2000;12:333-44.

37. Tariot PN, Ryan JM, Porteinsson AP, Loy R, Schneider LS. Pharmacological therapy for behavioral symptoms of Alzheimer's disease. Clin Geriatr Med 2001;17:359-76.

38. Hooper R, Osborne CA, Li KC, Swift CG, Jackson SHD. An indicator of appropriate neuroleptic prescribing in nursing homes. Age Ageing 2002;31:435-9.

39. Bezchlibnyk-Butler KZ, Jeffries JJ, Martin BA. Clinical Handbook of Psychotropic Drugs, 12th ed. Toronto: Hogrefe \& Huber, 2002.

40. Devanand DP, Sackheim HA, Mayeux R. Psychosis, behavioral disturbance, and the use of neuroleptics in dementia. Compr Psychiatry 1998;29:387-401.

41. Sunderland T, Silver MA. Neuroleptics in the treatment of dementia. Int J Geriatr Psychiatry 1998;3:784-90.

42. Earthy A, Collins J, Wong S, et al. Ensuring the appropriate use of neuroleptics. Can Nurs Home 2000;11:5-10.

43. Salzman C, Fisher J, Nobel K, et al. Cognitive improvement following benzodiazepine discontinuation in elderly nursing home residents. Int J Geriatr Psychiatry 1992; 7:89-93.

44. Beers MH. Explicit criteria for determining potentially inappropriate medication use by the elderly. Arch Intern Med 1997;157:1531-6.

45. Frels C, Williams P, Narayanan S, Gariballa SE. Iatrogenic cause of falls in hospitalised elderly patients: A case-control study. Postgrad Med J 2002;78:487-9.

46. Ray W, Fought R, Decker M. Psychoactive drugs and the risk of injurious motor vehicle crashes in elderly drivers. Am J Epidemiol 1992;136:873-83.

47. Sorensen L, Foldspang A, Gulmann NC, et al. Determinants for the use of psychotropics among nursing home residents. Int J Geriatr Psychiatry 2001;16:147-54.

48. Hanlon JT, Landerman LR, Wall WE, et al. Is medication use by community-dwelling elderly people influenced by cognitive function? Age Ageing 1996;25:190-6.

49. Teng EL, Chui HC. The modified mini-mental (3MS) state examination. J Clin Psychiatry 1987;48:314-8.

50. Tombaugh TN, McDowell I, Kristjansson B, Hubley AM. MiniMental State Examination (MMSE) and the Modified MMSE (3MS): A psychometric comparison and normative data. Psychol Assess 1996;8:48-59.

51. Tuokko H, Kristjansson B, Miller JA. The neuropsychological detection of dementia: An overview of the neuropsychological components of the Canadian Study of Health and Aging. J Clin Exp Neuropsychol 1995;17:325-73. 
52. American Psychiatric Association. Diagnostic and Statistical Manual of Mental Disorders, 3rd ed, rev. Washington, DC: American Psychiatric Association, 1987.

53. McKhann G, Drachman D, Folstein M, et al. Clinical diagnosis of Alzheimer's disease: Report of the NINCDS-ADRDA Work Group under the auspices of the Department of Health and Human Services Task Force on Alzheimer's disease. Neurol 1984;34:939-44.

54. Klein A, Kowall N. Alzheimer's disease and other progressive dementias. In: Volicier L, Hurley A, eds. Hospice Care for Patients with Advanced Progressive Dementia. New York: Springer, 1998:3-28.

55. Kaszniak AW, Ditraglia Christenson G. Differential diagnosis of dementia and depression. In: Storandt M, VandenBos GR, eds. Neurological Assessment of Dementia and Depression in Older Adults: A Clinician's Guide. Washington: American Psychological Association. 1994:81-117.

56. Sloane PD, Zimmerman S, Brown LC, et al. Inappropriate medication prescribing in residential care/assisted living facilities. J Am Geriatr Soc 2002;50:1001-11.

57. Gilman A, Hardman J, Limbird L. Goodman and Gilman's The Pharmacological Basis of Therapeutics, 10th edn. New York: McGraw-Hill, 2001.

58. Paton TW, Bell, M. Rheumatoid arthritis. In: Gray J, ed. Therapeutic Choices, 2nd ed. Ottawa: Canadian Pharmacists Association, 1998:392-9.

59. Peloso PM. Osteoarthritis. In: Gray J, ed. Therapeutic Choices, 2nd ed. Ottawa: Canadian Pharmacists Association, 1998:400-15.

60. Canadian Pharmacists Association. Compendium of Pharmaceuticals and Specialties, 34th edn. Ottawa: Canadian Pharmacists Association, 1999.

61. Katona CLE. Psychotropics and drug interactions in the elderly patient. Int J Geriatr Psychiatry 2001;16:S86-S90.

62. Baumgarten M, Becker R, Gauthier S. Validity and reliability of the Dementia Behavior Disturbance Scale. J Am Geriatr Soc 1990;38:221-6.
63. O'Rourke N, Tuokko HA. Psychometric properties of an abridged version of the Zarit Burden Interview within a representative Canadian caregiver sample. Gerontol 2003;43:21-7.

64. Tabachnick BG, Fidell LS. Using Multivariate Statistics, 4th edn. New York: Harper Collins, 2001.

65. American Geriatrics Society Panel on Chronic Pain in Older Persons. The management of chronic pain in older persons. J Am Geriatr Soc 1998;46:635-51.

66. Hernandez-Diaz S, Rodriquez LA. Association between nonsteroidal anti-inflammatory drugs and upper gastrointestinal tract bleeding/perforation: An overview of epidemiologic studies published in the 1990s. Arch Intern Med 2000;160:2093-9.

67. AGS Panel on Chronic Pain in Older Persons. The management of persistent pain in older persons. J Am Geriatr Soc 2002;50:S205-24.

68. Landi F, Onder G, Cesari M, et al. Pain management in frail, community-living elderly patients. Arch Intern Med 2001;161:2721-4.

69. Glass JR, Sproule BA, Herrmann N, Streiner D, Busto UE. Acute pharmacological effects of temazepam, diphenhydramine, and valerian in healthy elderly subjects. J Clin Psychopharmacol 2003;23:260-8.

70. Loring DW, Meador KI. Cognitive and behavioural effects of epilepsy treatment. Epilepsia 2001;42:24-32.

71. Lagnaoui R, Begaud B, Moore N, et al. Benzodiazepine use and risk of dementia: A nested case-control study. J Clin Epidemiol 2002;55:314-8

72. Beers MH. Explicit criteria for determining potentially inappropriate medication use by the elderly: An update. Arch Intern Med 1997;157:1531-6.

73. Roy R, Thomas MR, Cook AJ. Geriatric benign chronic pain: An overview. In: Block AR, Kremer EF, Fernandez E, eds. Handbook of Pain Syndromes: Biopsychosocial Perspectives. Mahwah, New Jersey: Lawrence Erlbaum Associates Inc, 1990:551-69. 


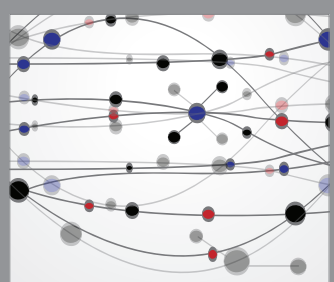

The Scientific World Journal
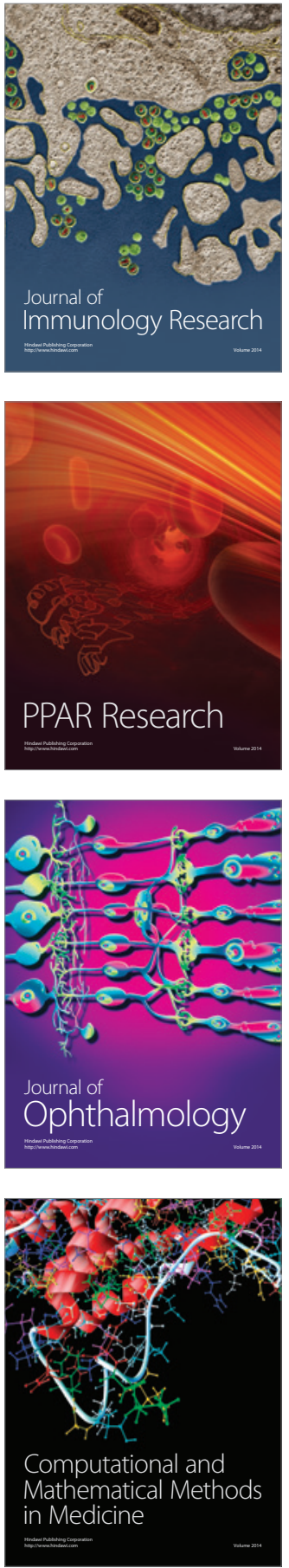

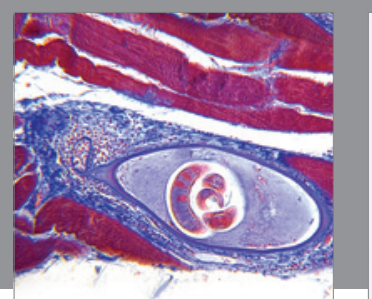

Gastroenterology Research and Practice

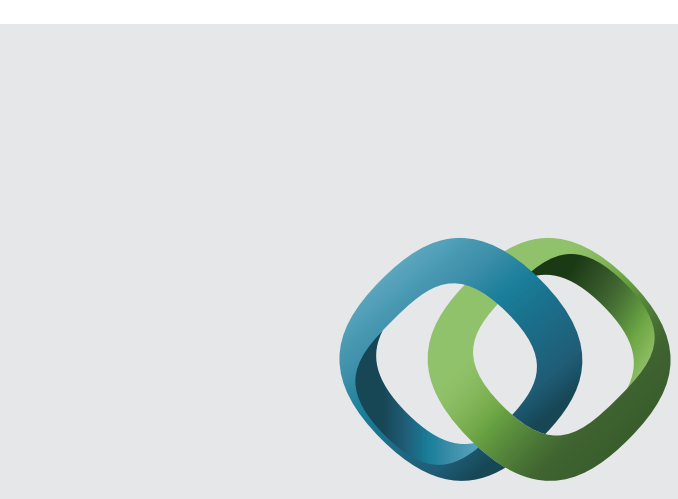

\section{Hindawi}

Submit your manuscripts at

http://www.hindawi.com
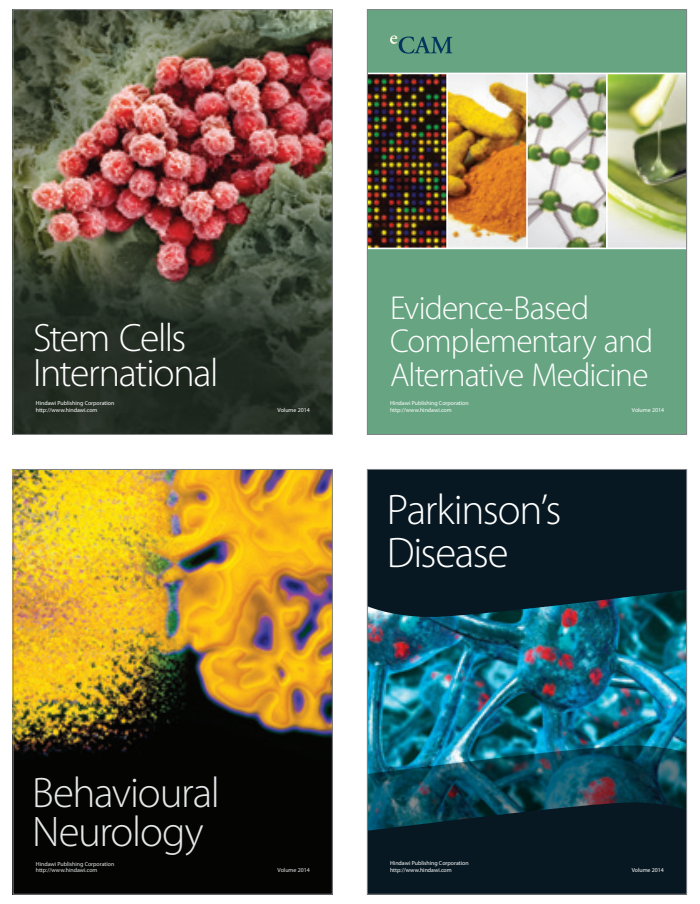
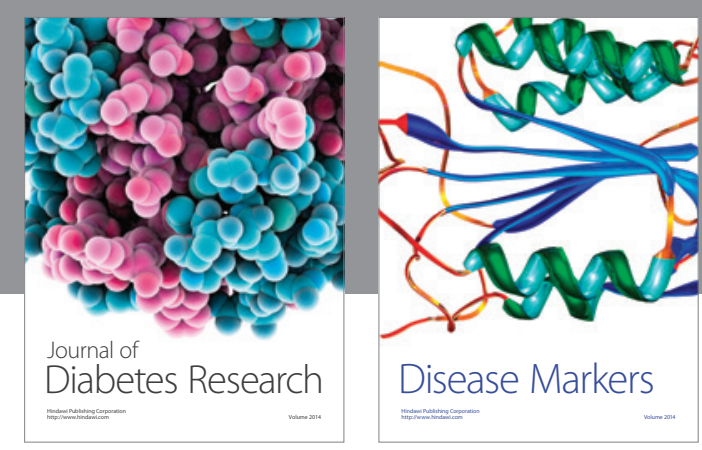

Disease Markers
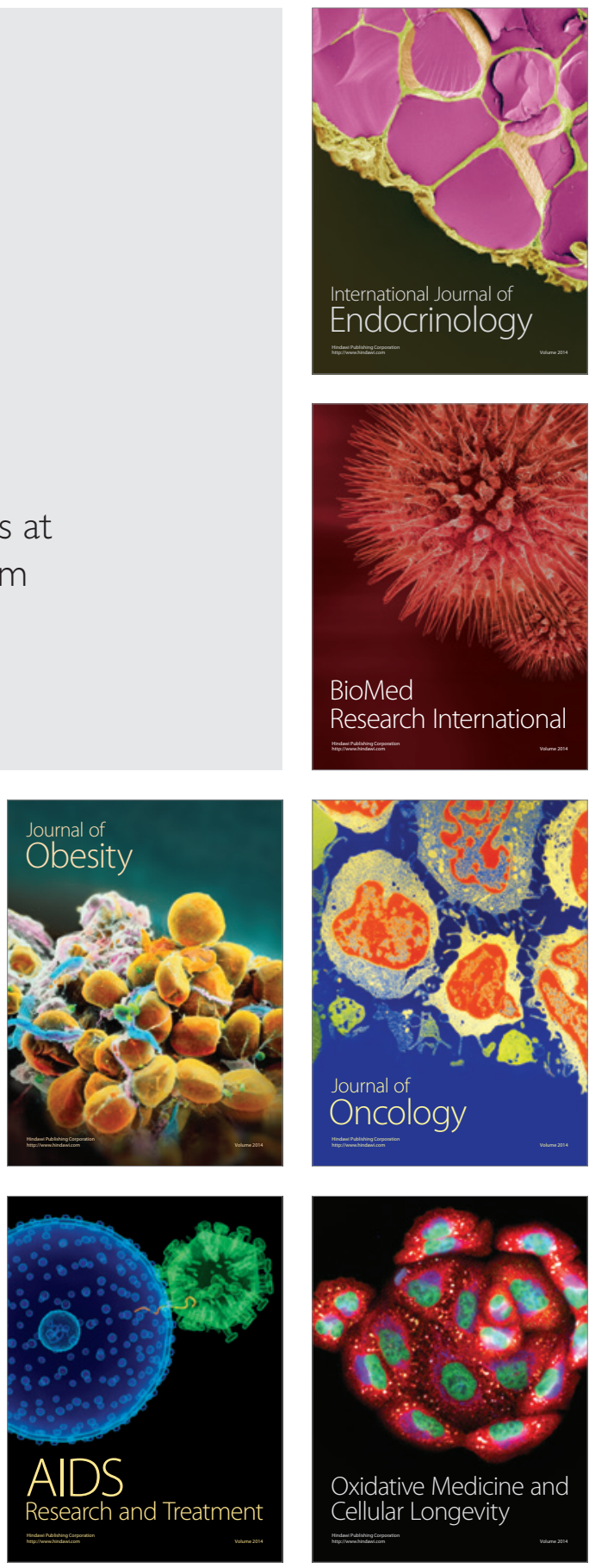